\title{
Rhinomanometric Assessment of Nasal Airflow in Deviated Nasal Septum
}

\author{
Vinit Kumar Sharma, Rohit Sharma
}

\begin{abstract}
Objective: The present study was carried out to study rhinomanometrically the nasal airflow in cases of deviated nasal septum and to compare rhinomanometric improvement following surgery with relief in subjective sensation of nasal airflow.
\end{abstract}

Materials and methods: This study was carried out in our institute from October 2009 to January 2011 including the cases of deviated nasal septum. A total number of 45 patients of deviated nasal symptoms were included in this study. Preoperative and postoperative assessment of nasal airflow were also assessed by rhinomanometry. Twenty cases were kept in control group to compare the nasal airflow.

Results: Good correlation was found between rhinomanometric results and improvement in subjective airflow sensation in patients who underwent septoplasty.

Conclusion: Usual methods of nasal examination, rhinomanometry seems to be of much more importance in understanding nasal airflow and selecting patients for operative intervention than previously thought.

Keywords: Nasal airflow, Rhinomanometry, Deviated nasal septum.

How to cite this article: Sharma VK, Sharma R. Rhinomanometric Assessment of Nasal Airflow in Deviated Nasal Septum. Clin Rhinol Int J 2012;5(1):17-18.

Source of support: Nil

Conflict of interest: None declared

\section{INTRODUCTION}

Nasal obstruction is a symptom not a disease and there are plethoras of conditions that can cause such symptoms. One of the commonest cause of nasal obstruction is deviated nasal septum. Nasal obstruction is probably the most often encountered chronic complaint in rhinological practice. The clinician is frequently confronted with the issue whether the septal deviation encountered during examination is responsible for patient's obstructive symptoms. ${ }^{1}$ In many cases the answer is not so straightforward as it may appear. Rhinomanometry is an objective test for quantitative estimation of nasal patency. It is useful for selecting patients in whom surgery can be expected to be beneficial in terms of improvement in nasal patency. Rhinomanometry measures the nasal patency utilizing the physics of airflow. Air will only flow through a tube when there is pressure difference between two ends in rhinomanometry. ${ }^{2-4}$

We continuously measure the pressure external to the nose and retronasal space. Apart from clinical evaluation of nasal obstruction, rhinomanometry can help to assess the patients of sleep apnea syndrome, allergy challenge test, nasopharyngeal patency, velopharyngeal functions and medicolegal assessment. Thus, unlike past rather than being a research tool, rhinomanometry appears to be an important investigatory tool in assessing the patients after any medical or surgical intervention. ${ }^{5}$

\section{AIMS AND OBJECTIVES}

1. To study rhinomanometrically the nasal airflow in cases of deviated nasal symptoms.

2. To compare rhinomanometric improvement following surgery with relief in subjective sensation of nasal airflow.

3. To study whether rhinomanometry is useful in better case selection in the decision concerning operation.

\section{MATERIALS AND METHODS}

This study was carried out in the Department of ORL-HNS, SRMS Institute of Medical Sciences, Bareilly from October 2009 to January 2011. This study included the cases of deviated nasal septum. A total number of 45 patients were included in this study. All selected patients were subjected to detailed clinical history and examination, hematological tests, radiological and nasal airflow studies. Selection of patients was based upon clinical diagnosis of deviated nasal septum (DNS). Nasal airflow studies were conducted in the selected patients and in a control group. The apparatus, we used, was a self-made device simulating rhinomanometer. The airflow was measured as a function of change in the height of air column during quite breathing. The rhinomanometry was performed in decongested nose. All selected patients were examined rhinomanometrically before and after septoplasty operations. The p-value was calculated by applying student t-test to check the significance. Then study group was subjected to septoplasty and after a month of operation, they were again examined rhinomanometrically in the similar way. The values were compared with the preoperative values and the p-value was calculated by applying paired t-test to see, if there was significant difference in nasal airflow after the operative procedure. pvalue of $<0.01$ was considered highly significant, i.e. the difference in airflow was not by chance, the value $<0.05$ was also considered significant. The p-value of $>0.05$ was considered insignificant. Along with rhinomanometry patients were subjected to questionnaire regarding improvement in subjective sensation of airflow after surgery. Twenty cases were also chosen as control group. 


\section{RESULTS}

The results of rhinomanometry preoperatively are shown in Table 1. On applying test for significance we found that 23 patients had significant difference in nasal flow because of DNS. Six patients had highly significant obstruction because of DNS. The results in terms of rhinomanometric improvement are shown in Table 2. On comparing the preoperative and postoperative findings in nasal airflow rhinomanometrically, we found that 30 patients had significant improvement in their nasal aerodynamics after septoplasty or SMR operation. Four patients had highly significant improvement. A correlation between rhinomanometric improvement and improvement in subjective sensation was also studied. It was seen that out of 34 patients who showed rhinomanometric improvement, 29 patients felt better in subjective sensations shown in Table 3.

\section{DISCUSSION}

In our series, we found that nasal obstruction and associated nasal pathologies constitute a major portion of patients visiting outpatient department. Most of patients were male. When compared to other studies, the incidence in males was much higher. ${ }^{6}$ This difference seems to be due to social factors. The males in this part of world are much more outgoing as compared to females and more prone to accidents. When classified on the basis of position, anterior DNS was more common than the posterior deviation. Higher incidence of anterior DNS has also been shown in our study

\begin{tabular}{lcc} 
& \multicolumn{3}{c}{ Table 1: Airflow reduction due to DNS } \\
\hline$p$-value & No. of patients & Percentage \\
\hline$<0.05$ & 23 & 51.42 \\
$<0.01$ & 6 & 11.42 \\
$>0.05$ & 16 & 37.14 \\
\hline
\end{tabular}

Table 2: Rhinomanometric improvement following septal correction surgeries

\begin{tabular}{lcc}
$p$-value & No. of patients & Percentage \\
\hline$<0.05$ & 30 & 68.57 \\
$<0.01$ & 4 & 8.57 \\
$>0.05$ & 11 & 22.86 \\
\hline
\end{tabular}

Table 3: Rhinomanometric vs subjective improvement after surgery

\begin{tabular}{lcc} 
Assessment method & $\begin{array}{c}\text { No. of } \\
\text { improved patients }\end{array}$ & $\begin{array}{c}\text { No. of not } \\
\text { improved patients }\end{array}$ \\
\hline Rhinomanometry & 34 & 11 \\
Subjective sensation & 29 & 16 \\
\hline
\end{tabular}

as documented by other authors. ${ }^{7}$ Along with DNS compensatory lateral wall changes were also seen commonly. Rhinomanometric analysis showed significant decrease in airflow because of DNS. Postoperative rhinomanometric analysis showed that there was significant improvement in airflow that had DNS but few patients did not improve because they also had associated nasal valve deformities. Good correlation was found between rhinomanometric results and improvement in subjective airflow sensation in those patients who had DNS without concomitant nasal valve pathology as seen in different studies. ${ }^{8}$ While selecting patients for septoplasty, we found that rhinomanometry, in association with clinical evaluation, is an important tool in proper selection of patients for surgery. This has also been emphasized in a study by P Broms et al 1982. Rhinomanometry has been proved a suitable tool for assessing the nasal airflow resistance for several years. The method is not only easy but also reveals the anatomy of nose better than patient's own evaluation. Another advantage is the reproducibility of the method.

\section{REFERENCES}

1. Bailey B (Ed). Nasal functions and evaluation, nasal obstruction. Otorhinolaryngology (2nd ed); Newyork NY Lippincott-Raven 1998:335-44.

2. Barr GS, Tewary AK. Alteration of airflow and mucocilliary transport in normal subjects. J laryngology 1993;107:603-04.

3. Bjerrum P, Illum P. Treatment of seasonal allergic rhinitis with budesonoide and sodium cromoglycate allergy 1985;40:65-69.

4. Bonilla JS-D, McCaffrey TV, Kern EB. The nasal valve: A rhinomanometric evaluation of maximum nasal respirarory flows and pressure curves. Ann Oto Rhinolo Lryngol 1986;95:229-31.

5. Borum P. Nasal methacoline challenge; A test for the measurement of nasal reactivity. J Allergy Clin Immunol 1979;63:253-57.

6. Cass LJ, Measurement of total respiratory and nasal airflow resistance. JAMA 1967;199:396-98.

7. Clement Par, Dischoek EAV, van Stoop. Some physical data on passive anterior rhinomanometry. Rhinology 1987;16;149-65.

8. Fischer EW, Scadding GK, Lund VJ. The role of acoustic rhinomanometry in studying nasal cycle. Rhinology. 1972;26: 271-72.

\section{ABOUT THE AUTHORS}

\section{Vinit Kumar Sharma (Corresponding Author)}

Assistant Professor, Department of Otolaryngology and Head and Neck Surgery, Shri Ram Murti Smarak Institute of Medical Sciences, Bareilly, Uttar Pradesh, India, Phone: 09305111828 e-mail: drvineetsharma@rediffmail.com

\section{Rohit Sharma}

Associate Professor, Department of Otolaryngology and Head and Neck Surgery, Shri Ram Murti Smarak Institute of Medical Sciences Bareilly, Uttar Pradesh, India 